\title{
Unilateral Versus Bilateral Wrist Band in Alleviating Nausea and Vomiting in Post Cesarean Section
}

\author{
HALA M. HANAFY, Ph.D.*; GHADA E. EL-REFAYE, Ph.D.*; SHOKRY A. EL-SHERSHABY, M.D.** and \\ BOUSY A. EBRAHIM, M.Sc.* \\ The Department of Physical Therapy for Women's Health, Faculty of Physical Therapy, Cairo University* and \\ The Department of Obsteterics \& Gynaecology, International Islamic Center for Population Studies \& Research, Assisted \\ Reproductive Technology Unit, Al-Azhar University**, Egypt
}

\begin{abstract}
Background: Postoperative nausea and vomiting (PONV) is nausea and vomiting occurring within 24 hours after surgery. Acupressure by using wrist bands are used to decrease postoperative nausea and vomiting by stimulation of P6 acupoint.

Aim: This study designed to analyze the effect of unilateral wrist band versus bilateral wrist bands in decreasing postoperative nausea and vomiting.

Methods: Forty volunteers, women had cesarean section, were randomly sent to two equal groups in the number of (A\&B). Group (A) had unilateral wrist band before induction of anesthesia and removed 24 hours after operation, group (B) had bilateral wrist bands before induction of anesthesia and removed 24 hours after operation.
\end{abstract}

Main Measures: Assessment for all subjects in both groups (A\&B) was carried out by using Rhodes Index, immediately after operation and at 6 and 24 hours after operation.

Results: Both groups exhibited a reduction in PONV after the end of treatment program, when both groups (A\&B) were compared together, there is favoring of group $\mathrm{B}$. These results indicate that using of unilateral wrist band and bilateral wrist bands were effective methods in decreasing post cesarean section nausea and vomiting, but bilateral is more effective.

Key Words: Nausea - Vomiting - Wrist band - Cesarean section.

\section{Introduction}

NAUSEA is a subjective unpleasant wave like feeling in the back of the throat and/or stomach that signals imminent vomiting, which may or may not result in vomiting, whereas, vomiting is objective and is defined as the forceful elimination of the contents of the stomach through the mouth by the sustained action of abdominal muscles and the opening of the gastric cardia [1]

Correspondence to: Dr. Hala M. Hanafy, The Department of Physical Therapy for Women's Health, Faculty of Physical Therapy, Cairo University, Cairo, Egypt
Nausea and vomiting occur quite frequently under various conditions and can be triggered by different inputs or combinations of input mechanisms. Nausea and vomiting controlled by the central nervous system. Nausea is controlled by apart of the nervous system that controls involuntary body functions, however specific neural pathways have not been identified for nausea. Vomiting is a reflex, which is controlled by a vomiting center in the brain stem. The sensation of nausea and vomiting can be elicited by physiological, psychological, and environmental stimuli, such as an adverse drug reaction, postoperative changes during recovery, autonomic dysfunction, gastrointestinal dysfunction, mental stress, pain, smell, taste, motion, traumatic experiences, exposure to toxins and many other stimuli [2].

Complication of vomiting is esophageal perforation. In severe cases without thiamin supplementation; wernick's encephalopathy may occur (i.e. nystagmus, disorientation, confusion and coma). If treatment is unsuccessful, complications of prolonged dehydration and starvation may occur [1]

Postoperative nausea and vomiting (PONV) is defined as nausea and vomiting occurring within 24 hours after surgery which can lead to significant adverse physical, metabolic, and psychologic consequences for the surgical patients. PONV is a leading complication of surgery and often is viewed by patients as the single most stressful side effect of anesthesia and the operative period [3] .

Over 40 million patients undergo surgery per year in the United States and more than 100,000,000 patients worldwide with about $30 \%$ experiencing postoperative nausea and vomiting. Even patients with zero risk factors carry a $10 \%$ risk of PONV. 
This risk increases dramatically to $61 \%$ and $79 \%$, respectively, when 3 or 4 risk factors exist (female gender, nonsmoker, history of motion sickness, postoperative opioid use, and a history of PONV) [4].

Routine prophylaxis would seem appropriate, but the choice of anti-emetic agents is wide, and some are too expensive to be cost-effective for routine use. While today's health care system is focusing on the reduction of expenditures and resources $[\mathbf{5 , 6 ]}$. The side effects associated with these anti-emetic agents can include headaches, constipation, agitation, tachycardia, extrapyramidal effects, sedation and even possibly prolonged QT intervals and fatal arrhythmia [7].

A non-invasive alternative PONV preventative is acupressure. This ancient naturopathic science is based on a non-pharmacological theory that differs radically from modern allopathic medicine. Acupuncture of p6 (Neiguan) is used for treatment of nausea and vomiting in traditional Chinese medicine. Recently, many clinical investigations have shown that stimulation of the $\mathrm{p} 6$ acupoint with non-invasive acupressure can prevent vomiting caused by early pregnancy, surgical procedures and chemotherapy [8]

P6 is found between the two major tendons (Palmarislongus and flexor carpi radials tendons) on the inside of the arm, approximately two inches, or three finger widths, below the crease of the wrist. Techniques to stimulate P6 acupoint include: acupuncture, electro-acupuncture, laser acupuncture, transcutaneous electrical nerve stimulation (TENS), and acupressure [9,10]. Wrist Bands used for the application of acupressure to the $\mathrm{p} 6$ point. These bands are British made, commercially available; contain a stud in an elasticized band. It is comfortable and fits all wrist sizes. Wrist band can be re-used, wash in a gentle cycle, no special storage conditions needed and shelf-life unlimited [11].

\section{Patients and Methods}

Forty women having cesarean section had been selected randomly from Obstetrics and Gynecology unit of Said Galal Hospital, from May 2015 - May 2016 Cairo shared in this study with the following criteria: All females were having cesarean section, their ages were ranged from 20 to 35 years old. The exclusion criteria included the following: Women had previous carpal tunnel syndrome, or had experienced nausea and vomiting within 24 hr prior to C.S., or have diabetes or hypertension or skin abnormalities or acute viral disease, all participated women signed an informed consent form. The study approved by the faculty of physical therapy ethics committee.

\section{Randomization:}

An independent person randomly assigned to all participated women to either group $(A)(n=20)$ or group (B) $(n=20)$ by chosen numbers from closed envelopes having numbers that the number generator were chosen randomly. These randomization was restricted to different sizes permuted blocks to make sure that equal numbers were assigned to each group (A) and (B).

They were divided randomly into two equal groups: Group (A) 20 women were treated by unilateral wrist band. While the group (B) 20 women were treated by bilateral wrist bands.

\section{Assessment:}

The Rhodes index of nausea, vomiting and retching (RINVR) is an instrument consisting of eight 5-point self-report items, designed to assess subjective and objective factors of nausea, vomiting and retching in various situations [12]. A recent study demonstrated the reliability of the RINV for ambulatory surgery patients [13].

Positive events of nausea, vomiting or retching with 6 hours after surgery were designated as early PONV, while positive events of nausea, vomiting or retching between 6 and 24 hours after surgery were designated as late PONV.

Assessment was done immediately after the operation, at 6 and 24 hours post operation.

\section{Treatment procedures:}

A full history was taken from each woman in both groups (A) and (B) before starting this study, each patient was instructed carefully about the evaluation procedure. A consent form was signed by each patient before participating in the study.

\section{Wrist bands:}

\section{Participants in group (A):}

Twenty participants in group (A) had unilateral wrist band, on P6 point above wrist crease by 3 fingers breadth between the tendons of flexor carpi radialis and Palmaris longus muscles. Wrist band is elasticized band with a large plastic stud that is easily positioned over P6. The skin was free of oils and lotions and cleaned prior to the application. The wrist band was applied before operation, the participants lied in comfortable position. The band was removed 24 hours after C.S. 


\section{Participants in group (B):}

Twenty participants in group (B) had bilateral wrist bands, on P6 point. The wrist bands were applied before operation, while the participants lied in comfortable position. The bandswas removed 24 hours after C.S. (Fig. 1).
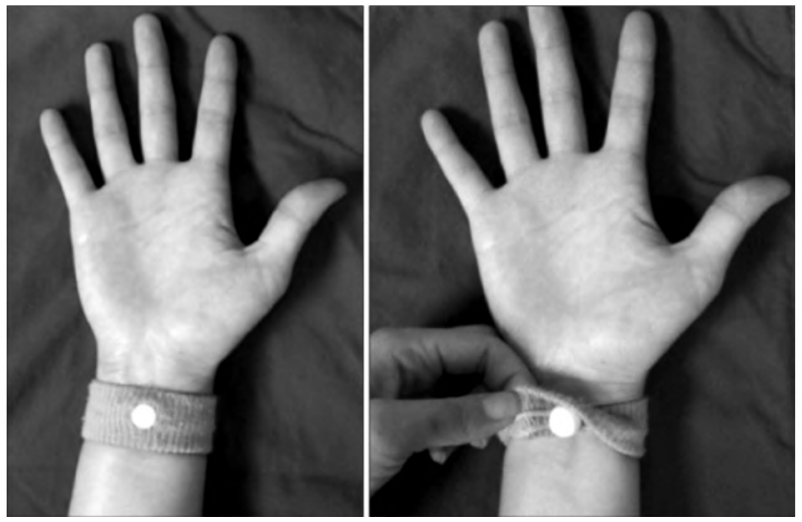

Fig. (1): Point of application of wrist band (P6).

\section{Statistical analysis:}

Data was summarized using: The arithmetic mean, the standard deviation, the percentage (for qualitative variables). Statistical analysis was used in the form of paired $t$-test to compare between means in the same group. Unpaired $t$-test was used to compare means between different groups. The Statistical Package for the Social Sciences (SPSS) computer programs was used for data analysis. $p$-value $\leq 0.05$ were expressed as a significant.

\section{Results}

In our study the population consisted of 40 women, after cesarean section, with mean age of (27.4 \pm 4.07$)$ years at group A (unilateral) and (26.2 \pm 4.96$)$ years at group B (bilateral). There was no statistical significant difference in the mean values of age between the two groups (A\&B) (Table 1).

Show the statistically insignificant relation between age and group (Unilateral \& Bilateral). The mean BMI of group A (unilateral) is (32.2) $\mathrm{kg} / \mathrm{m}^{2}$ and of group B (bilateral) is $(32.25) \mathrm{kg} / \mathrm{m}^{2}$. There was no statistical significant difference in the mean values of BMI between the two groups (A\&B) (Table 2).

There was a statistical significant decrease in frequency of vomiting in group A(unilateral) with $p$-value $=0.001$ and chi-square test $=17.9$, also there was a statistical significant decrease in frequency of vomiting in group B (bilateral) with $p$-value $=0.013$ and chi square test $=12.7$. $($ Table 3$)$.

At the end of the treatment program, after the comparison between the two studied groups, there is favoring of the group B (bilateral) in treatment of PONV.

Table (1): Relation between age and group (Unilateral \& Bilateral).

\begin{tabular}{lccc}
\hline \multirow{2}{*}{ Statistics } & \multicolumn{3}{c}{ Age of patient } \\
\cline { 2 - 3 } & $\begin{array}{c}\text { Group A } \\
\text { Unilateral }\end{array}$ & $\begin{array}{c}\text { Group B } \\
\text { Bilateral }\end{array}$ & \\
\hline Mean \pm SD & $27.400 \pm 4.0704$ & $26.200 \pm 4.969$ & $t=.0 .835$ \\
Minimum & 20.00 & 20.00 & $p=.0 .409$ \\
Maximum & 33.00 & 34.00 & \\
\hline
\end{tabular}

Table (2): Relation between BMI and group (Unilateral \& Bilateral).

\begin{tabular}{lccc}
\hline \multirow{2}{*}{ Statistics } & \multicolumn{3}{c}{ BMI of patient } \\
\cline { 2 - 3 } & $\begin{array}{c}\text { Group A } \\
\text { Unilateral }\end{array}$ & $\begin{array}{c}\text { Group B } \\
\text { Bilateral }\end{array}$ & \\
\hline Mean \pm SD & $32.200 \pm 1.1854$ & $32.250 \pm 1.2513$ & $p=0.897$ \\
Minimum & 30.00 & 30.00 & $t=1.3$ \\
Maximum & 35.00 & 34.00 & \\
\hline
\end{tabular}

Table (3): Distribution of Frequency of vomiting according to time and Wrist band group (Unilateral \& Bilateral)

\begin{tabular}{|c|c|c|c|c|}
\hline \multirow{2}{*}{ Wrist group } & \multicolumn{3}{|c|}{ Time } & \multirow{2}{*}{ Test of sig. } \\
\hline & 0 & 6 & 24 & \\
\hline \multicolumn{5}{|l|}{$\begin{array}{l}\text { Unilateral: } \\
\text { Medium: }\end{array}$} \\
\hline $\mathrm{N}$ & 4 & 0 & 0 & \multirow[b]{4}{*}{$\begin{array}{l}\chi^{2}=17.9 \\
p=0.001\end{array}$} \\
\hline$\%$ & 20.0 & .0 & .0 & \\
\hline \multicolumn{5}{|l|}{ Low: } \\
\hline $\begin{array}{l}\mathrm{N} \\
\%\end{array}$ & $\begin{array}{l}8 \\
40.0\end{array}$ & $\begin{array}{l}7 \\
35.0\end{array}$ & $\begin{array}{l}1 \\
5.0\end{array}$ & \\
\hline $\begin{array}{l}\text { None: } \\
\mathrm{N} \\
\%\end{array}$ & $\begin{array}{l}8 \\
40.0\end{array}$ & $\begin{array}{l}13 \\
65.0\end{array}$ & $\begin{array}{l}19 \\
95.0\end{array}$ & \\
\hline \multicolumn{5}{|l|}{ Bilateral: } \\
\hline $\begin{array}{l}\mathrm{N} \\
\%\end{array}$ & $\begin{array}{l}3 \\
15.0\end{array}$ & $\begin{array}{l}0 \\
.0\end{array}$ & $\begin{array}{l}0 \\
.0\end{array}$ & \multirow{3}{*}{$\begin{array}{l}\chi^{2}=12.7 \\
p=0.013\end{array}$} \\
\hline $\begin{array}{c}\text { Low } \\
\mathrm{N} \\
\%\end{array}$ & $\begin{array}{l}5 \\
25.0\end{array}$ & $\begin{array}{l}3 \\
15.0\end{array}$ & $\begin{array}{l}0 \\
.0\end{array}$ & \\
\hline $\begin{array}{c}\text { None: } \\
\mathrm{N} \\
\%\end{array}$ & $\begin{array}{l}12 \\
60.0\end{array}$ & $\begin{array}{l}17 \\
85.0\end{array}$ & $\begin{array}{l}20 \\
100.0\end{array}$ & \\
\hline
\end{tabular}




\section{Discussion}

Post-operative nausea and vomiting (PONV) is a common complication after surgery. Incidence of PONV has been described to be as high as 60$80 \%$ in some studies. Multiple studies have emphasized the economic burden of PONV and its effect on post-operative recovery [14] .

Patients are suggested to receive prophylactic anti-emetic agents, but these drugs may be accompanied by some undesirable side effects. An alternative for these modern anti-vomiting medications is the traditional eastern medicine, it has been used for thousands of years for treating nausea and vomiting in the eastern world [15]. Acupressure is application of pressure on a specific point (NeiGuan) on the volar side of forearm, $2 \mathrm{~cm}$ proximal to the wrist crease, between the tendons of Palmaris longus and flexor carpi radialis [16].

Since the problem of PONV is widely recognized, although it has been known that acupressure could effectively decrease PONV, but this modality have not yet been used in clinical practice for alleviating PONV. So this study was conducted to compare the effect of acupressure using wrist band unilaterally vs. bilaterally on decreasing nausea and vomiting after C.S.

For that, forty women having cesarean section were selected from obstetrics and gynecology unit at Said Galal hospital in Cairo, they had been enrolled in 2 equal groups in number: Group (A) had unilateral wrist band before induction of anesthesia, group (B) had bilateral wrist bands before induction of anesthesia, and bands are removed after 24 hours post-operatively.

The results of the presenting study revealed that, unilateral and bilateral wrist bands were effective adjunct methods in reducing post C.S. nausea and vomiting.

There was a highly statistically significant reduction of nausea and vomiting in both groups after the end of the treatment program, when both groups were compared together, there was statistical significant difference in PONV between both groups favoring the group $\mathrm{B}$ (bilateral) than the group A (unilateral).

Previous studies in that field support these finding, in Allen and Habib [17] carried out a systematic review that compared the overall efficacy of different methods of P6 stimulation with placebo in women having caesarean delivery under neuraxial anesthesia. The primary outcomes includ- ing the incidence of nausea, vomiting, and the need for rescue antiemetic therapy, both intra-operatively and post-operatively. Six studies involving 649 patients were included. Of these, two studies reported a significant reduction in the incidence of intra-operative nausea with P6 stimulation, and one study reported a significant reduction in rescue antiemetic requirement. However, none of the studies reported any differences between the treatment and control groups with respect to vomiting. Four studies reported post-operative outcomes. Of these, one study reported a significant reduction in post-operative nausea, two studies reported a significant reduction in post-operative vomiting, and one study reported a significant reduction in the need for post-operative rescue antiemetic therapy.

As well as, Lee and Fan [18] carried out a systematic review that assessed the efficacy and safety of P6 acupoint stimulation in preventing postoperative nausea and vomiting (PONV). Forty randomized controlled trials involving 4,858 participants of techniques that stimulated the P6 acupoint compared with sham treatment or drug therapy for the prevention of PONV were included. Interventions used included acupuncture, electroacupuncture, transcutaneous nerve stimulation, laser stimulation, an acu-stimulation device, and acupressure in patients undergoing surgery. Primary outcomes were the risks of nausea and vomiting. Secondary outcomes were the need for rescue antiemetic therapy and adverse effects. Compared with sham treatment P6 acupoint stimulation significantly reduced: Nausea, vomiting and the need for rescue anti-emetics. There was no clear difference in the effectiveness of P6 acupoint stimulation for invasive and noninvasive acupoint stimulation. There was no evidence of difference between P6 acupoint stimulation and antiemetic drugs in the risk of nausea, vomiting, or the need for rescue anti-emetics.

Also Frey et al., [19] carried out a randomized controlled trial that investigated the effectiveness of acustimulation in relation to known risk factors for PONV. Two hundred women undergoing vaginal hysterectomy were given 24 hours of acustimulation or sham stimulation. Nausea and vomiting/retching was recorded for 24 hours after operation in the whole group and stratified by risk factors. The incidence of PONV and need for rescue therapy was significantly lower in the acustimulation than in the sham group.

This was supported by Soltaniet al., [20] carried out a randomized controlled trial that compared 
the clinical efficacy of acupressure with ondansetron or metoclopramide for postoperative nausea and vomiting (PONV) after strabismus surgery. There were 200 patients included. Acupressure wrist bands were applied 30 minutes before anesthesia induction and removed six hours after surgery. PONV was evaluated within 0-2 hours and 2-24 hours after surgery by a blinded observer. The researchers concluded that acupressure at P6 on the wrist causes a significant reduction in the incidence and severity of PONV 24 hours after strabismus surgery, which is similar to the reduction seen with metoclopramide and ondansetrone.

In addition, Lee and Fan., [10] included 40 randomized trials of techniques that stimulated the P6 acupoint compared with sham treatment or drug therapy for the prevention of PONV. Interventions used in these trials included acupuncture, electroacupuncture, transcutaneous nerve stimulation, laser stimulation, an acu-stimulation device and acupressure in patients undergoing surgery. Primary outcomes were the risks of nausea and vomiting. Secondary outcomes were the need for rescue antiemetic therapy and adverse effects. Authors concluded that P6 acupoint stimulation prevented PONV. There was no reliable evidence for differences in risks of postoperative nausea or vomiting after P6 acupoint stimulation compared to antiemetic drugs.

This finding is in agreement with Norooziniaet al., [21] in a study examined acupressure as a safe complement to the more traditional approach of using drugs to prevent and/or relieve nausea and vomiting in the Cesarean section under spinal anesthesia. In a prospective randomized clinical trial, 152 patients who were candidate for elective $\mathrm{C} / \mathrm{S}$ under spinal anesthesia were evaluated in two groups (acupressure vs. control groups). Subjects in the acupressure group received constant pressure by wrist band on P6 acupuncture point, 30min prior to spinal anesthesia. The incidence of PONV was assessed during the surgery, at recovery room and at 1 st, 2 nd and 3 rd two hours after the surgery. Significant differences in the incidence of the postoperative nausea and vomiting were found between the acupressure and control groups, with a reduction in the incidence rate of nausea from $35.5 \%$ to $13.2 \%$. The amount of vomitus and the degree of discomfort were, respectively, less and lower in the study group. In view of the total absence of side-effects in acupressure, its application is worthy. The study confirmed the effectiveness of acupressure in preventing post-operative nausea and vomiting.
This work was supported by Agarwalet al., [14] carried out a randomized control trial on 300 patients undergoing obstetric surgery under spinal anesthesia. The patients were randomly allocated in four groups using a random sequence. In group I, 98 patients received metoclopramide $0.2 \mathrm{mg} . \mathrm{kg}$ intravenous (IV) 5 minutes prior to induction of anesthesia. In group II, 102 patients received 75 tg palonosetron IV 5 minutes prior to induction. Group IIIA contained 51 patients in acupressure (wrist band) group. Group IIIB include 49 patients in acupressure with capsaicin paste. All patients were followed till 24 hours post-surgery and incidence of PONV was recorded intra-operative and till 30 minutes, at 2 hours, 6 hours and 24 hours post-surgery. Authors concluded that acupressure wrist band is a safe and highly effective method to prevent PONV, even in emergency settings and high risk patients. The acupressure wristband can help in bringing down cost and can be easily made.

This is consistent with Norheim et al., [22] in a study on the effect of pressure medicine on nausea and vomiting following cesarean section showed that pressure medicine reduces both vomiting during the operation and nausea and vomiting after surgery. Also Coloma et al., [23] compared acustimulation with ondansetron for the treatment of established PONV in outpatient laparoscopic surgery patients. They concluded that acustimulation may be a satisfactory alternative to ondansetron seems to enhance the efficacy of acustimulation for treatment of established PONV.

In addition Afhami et al., [24] in an investigation showed that the acupressure on P6 point is influential for nausea and vomiting. As well as Naseriet al., [25] in an investigation showed that acupressure on P6 point is a useful method to decreasing the nausea and vomiting in adults after orthopedic surgeries.

This was supported by Lee and Done, [26] in a review of 26 clinical trials into stimulation of acupoint P6 for preventing postoperative nausea and vomiting. Methods used including needle acupuncture, electro-acupuncture, laser stimulation and acupressure, the authors found that stimulating P6 was more effective than sham treatment (stimulating a non-acupuncture point) in reducing the risk of nausea, vomiting and need for rescue antiemetics.

Also Wang and Kain, [27] found that P6 acupuncture as effective as the anti-emetic droperidol in controlling postoperative nausea and vomiting in 187 children in the recovery ward. In addition 
Harmon et al., [28] applied sea-Bands to the P6 acupoint five minutes before the anesthetic and removed six hours after cesarean, acupressure was found to reduce the incidence of nausea or vomiting from $53 \%$ to $23 \%$ compared with a placebo.

This work was supported by Ezzo et al., [19] with 26 trials and more than 3,000 patients showing that P6 stimulation was more effective in postoperative nausea and vomiting than sham in both adults and children and for both nausea and vomiting, also trials including different anti-emetics showed that P6 stimulation seems to be superior to anti-emetic medication for nausea and equivalent for vomiting.

\section{Conclusion:}

The bilateral wrist band had significant effect than unilateral in decreasing frequency of vomiting, immediately after cesarean section, at $6 \mathrm{~h}$. and $24 \mathrm{~h}$. Post-operative, so both methods of treatment can be considered as good alternative modalities in decreasing PONV. However there is a superiority of bilateral wrist bands than unilateral wrist band in decreasing PONV.

\section{Consent:}

All authors revealed that written informed consent was recorded by all the patients before starting the study.

\section{Competing Interests:}

Authors have revealed that there was no competing interests exist.

\section{Acknowledgement:}

Many thanks, to all patients who participated in the study for their co-operation.

\section{References}

1- GAN T., SIOAN F. and DEAR GDE L.: How much are patients willing to pay to avoid postoperative nausea and vomiting? Anesth. Analg., 92: 393-400, 2001.,

2- ABHAY R., KAREN M. and GARY R.: The pathophysiology of treatment-related nausea and vomiting in cancer patients: Indian. J. Physiol. Pharmacol., 48 (3): 256-268, 2004.

3- GAN T.: Postoperative nausea and vomiting: Can it be eliminated ? JAMA, 287: 1233-1236, 2002.

4- ROBERTS S., BEZINOVER D. and JANICKI P.: Reappraisal of the role of dolasetron in prevention and treatment of nausea and vomiting associated with surgery or chemotherapy. Cancer. Manag. Res., 4: 67-73, 2012.

5- AGARWAL A., PATHAK and GAUR A.: Acupressure wrist bands do not prevent postoperative nausea and vomiting after urological endoscopic surgery. Can. J. Anseth., 47: 319-324, 2000.
6- LANGER R.: Postoperative nausea and vomiting, Accessed November 14, 2002.

7- KOTANI N., HASHIMOTO H., SATO Y., SESSLER D., YOSHIOKA H. and KITAYAMA M.: Preoperative intradermal acupuncture reduces postoperative pain, nausea and vomiting, analgesic reqirment and sympathodernal responses. Anesthesiology, 95: 349-356, 2001.

8- GAN T., JIAO K. and GEORGIADE G.A: randomized controlled comparison of electro-acupoint stimulation or ondansetron versus placebo for the prevention of postoperative nausea and vomiting. Aneth Analg., 99: 10701075, 2004.

9- EZZO J., RICHAREDSAN M., VICKERS A., ALLEN C., DBBLE S., ISSEL B., LAO L., PEAL M., RAMRES G., ROSCOE J., SHEN J., SHIVNAN J., STREITBERGER K., TREISH L. and ZHANG G.: Acupuncture point stimulation for chemotherapy induced nausea or vomiting (Review). The Cochrane Library, Issue 4, 2006.

10- LEE A. and FAN L.: Stimulation of the wrist acupuncture point P6 for preventing postoperative nausea and vomiting. Cochrane Data base Syst. Rev., (2): 10-1002, 2011.

11- WINDLE P., BORROMEO A., ROBLES H. and ILACIOU.: The effects of acupressure on the incidence of postoperative nausea and vomiting in post surgical patients. J. Peri. Anesth. Nursing, 16: 158-162, 2001.

12- RHODES V. and Mc DANIEL R.: The index of nausea, vomiting, and retching: A new format of the Index of nausea and vomiting. Oncol. Nurs. Forum., 26: 889-94, 1999.

13- FETZER S., HAND M., BOUCHARD P., SMITH H. and JENKINS M.: Evaluation of the Rhodes index of nausea and vomiting for ambulatory surgery patients. J. Adv. Nurs., 47: 74-80, 2004.

14- AGARWAL A., JHA R., AGARWAL S., TYAGI C. and GUPTA R.: A study comparing efficacy of P6 acupressure point, Palanosetron and Metoclopramide in prevention of postoperative nausea and vomiting after obstetric surgeries., 5 (3): 1238-1245, 2016.

15- MILLER R., ERIKSSON L., WIENER-KRONISH J. and YOUNG W.: Postoperative Nausea and Vomiting. In: Miller's Anesthesia. Chapter 86: Churchill Livingstone/ Elsevier., Vol. 2, 7 th ed, 2009.

16- GOLEMBIEWSKI J., CHERNIN E. and CHPRA T. Prevention and treatment of postoperative nausea and vomiting. Am. J. Health. Syst. Pharm., 62 (12): 1247-60, 2005.

17- ALLEN T. and HABIB A.: P6 stimulation for the prevention of nausea and vomiting associated with cesarean delivery under neuraxial anesthesia: A systematic review of randomized controlled trials. Anesthesia and Analgesia, 107: 1308-12, 2008.

18- LEE A. and FAN L.: Stimulation of the wrist acupuncture point P6 for preventing postoperative nausea and vomiting. Cochrane Database of Systematic Reviews. Issue 2. Pub 3, 2009.

19- FREY U., SCHARMANNP., LOHLEIN C. and PETERS J.: P6 acustimulation effectively decreases postoperative nausea and vomiting in high-risk patients. Br. J. Anaeth., 102: 620-5, 2009. 
20- SOLTANI A., ARBABI S., GOUDARZI M. and SAMIMI M.: Acupressure using ondansetron versus metoclopramide on reduction of postoperative nausea and vomiting after strabismus surgery. Archives of Iranian Medicine, 13: 288-93, 2010

21- NOROOZINIA H., MAHOORI A., HASANI E., GERAMI M. and SEPEHRAVAND N.: The Effect of Acupressure on Nausea and Vomiting after Cesarean Section Under Spinal. Anesthesia., 51 (3): 163-167, 2013.

22- NORHEIM A., PEDERSEN E., FONNEBO V. and BERGE L.: Acupressure treatment of morning sickness in pregnancy. Scand. J. Prim. Health. Care., 19: 43-47, 2001.

23- COLOMA M., WHITE P., OGUNNAIKE B., MARKOWITZ S. and BROWN P., LEE A.: Comparison of acustimulation and ondansetron for the treatment of established postoperative nausea and vomiting. Anesthesiology, 97: 1387-92, 2002.

24- AFHAMI M., TADAYON M. and SESSLER D.: Method of non medicinal in prevention of nausea and vomiting in cesarean section by spinal anesthesia. Medical Journal, Tabriz University of Medical Sciences, 59: 14-18, 2003.
25- NASERI K., SHAMI S., AHSAN B. and ZOJAJI KOHAN M.: Effect of acupressure on post operative nausea and vomiting Hormozgan Medical Journal, 10 (4): 357-362, 2006.

26- LEE A. and DONE M.: Stimulation of the wrist acupuncture point P6 for preventing postoperative nausea and vomiting. Cochrane Data base of systematic Reviews, (3): 3281,2004

27- WANG S. and KAIN Z.: P6 acupoint injections are as effective as droperidol in controlling early postoperative nausea and vomiting in children. Anesthesiology, 97 (2): 359-66, 2002.

28- HARMON D., RYAN M., KELLY A. and BOWEN M. Acupressure and prevention of nausea and vomiting during and after spinal anaesthesia. British Journal of Anesthesia, 82 (3): 387-90, 2000

29- EZZO J., STREITBERGER K. and SCHNEIDER A.: Cochrane systematic reviews examine P6 acupuncturepoint stimulation for nausea and vomiting. Journal of Alternative and Complementary Medicine, 12: 489-95, 2006.

\section{مقارنة بين تأثير عصابة اليد الاحادية والثنائية

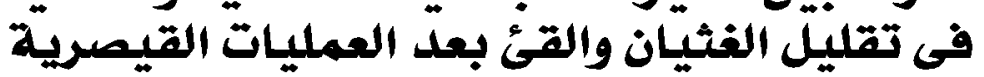

$$
\text { يعرف الثثيان والقئ بعد العمليات الجراحية بانه الفثيان والقئ الذى يحدث خلال اريع وعشرن سعاعة بعد الجراحة . }
$$

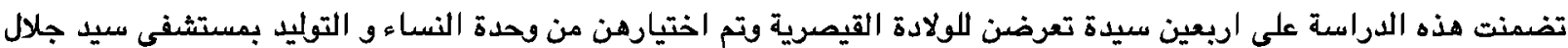

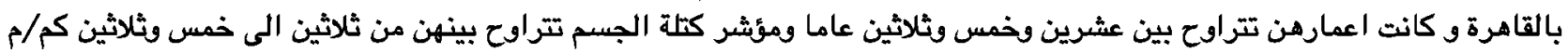
وتم تقسيمهن الى مجموعتين متساويتين فى العدد بطريقة عشوائية: المجموعة الاولى (أ): احتوت على عشرين سيدة وضعت عصابة يد احادية قبل الدخل الى غرفة الممليات. المجموعة الثانية (ب):احتوت على عشرين سيدة وضعت عصابة يد ثنائية قبل الدخول الى غرفة العمليات.

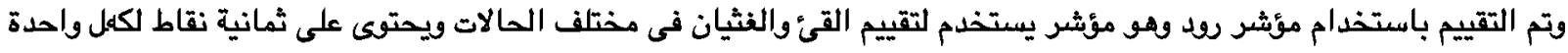
خمس خانات. وتم عمل التقييم بعد الخدوج من غرفة العمليات مباشرة وبعد ست ساعات واريع وعشرين ساعة.

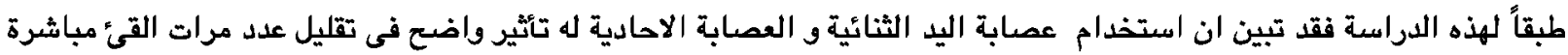

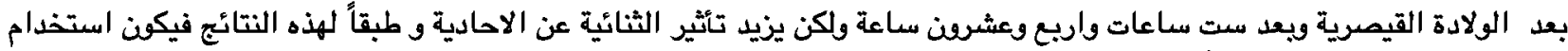

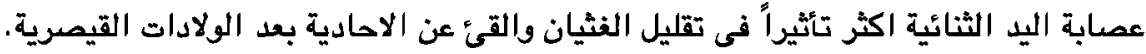

